International Journal of Child, Youth and Family Studies (2014) 5(1): 70-88

\title{
FAMILY AND YOUTH VULNERABILITY TO SUICIDAL BEHAVIOUR IN FIRST NATIONS: A COMPARISON OF RESERVE AND NON-RESERVE GROUPS
}

\author{
Michel Tousignant, Nathalie Morin, Livia Vitenti, \\ Antoine Bibaud De Serres, and Arlene Laliberté
}

\begin{abstract}
Family factors can influence vulnerability to suicide in the general population as well as among Aboriginal communities. This research compares First Nations families living in three contexts - on a reserve, in a small town, and in a metropolitan area - to verify if children on a reserve appear to have higher family vulnerability, as indicated by a measure of negligence/indifference. An interview was conducted with three non-random samples of Quebec First Nations parents. The first sample was selected from a reserve, the second from families living in small towns near a reserve, and the third from two metropolitan areas. The negligence score was based on the criteria of the Childhood Experience of Care and Abuse interview. Aboriginal families from the metropolitan areas obtained a lower rate of negligence than the reserve group, with an intermediate rate for the small town group. However, rates were high in all three settings. Informants from groups outside the reserve perceived the reserve as presenting more challenges to raising children than where they lived. Vulnerability of children is likely to remain high in this reserve in the near future. Initiatives that have the intention of empowering parents should be undertaken at the family level. Prevention should also focus on ecological factors such as housing, continuing education, and job creation, as well as family intervention.
\end{abstract}

Keywords: First Nations, suicide prevention, parental behaviour

Acknowledgement: This research was funded by the Canadian Institutes of Health Research of Canada (grant SAN 79157). We thank all the participants from the First Nations families who have contributed to this research. We also want to thank the following persons: Alex Cheezo, Jean Papatie, Alexandre Auger, Danielle Rousselot, Felipe Benedet Maureira, Alain Janelle, Élisha Laprise, and Remi Castonguay.

Michel Tousignant, Ph.D. (the corresponding author) is an Associate Professor in the Department of Psychology and the Center for Research and Intervention on Suicide and Euthanasia, University of Quebec in Montreal, Postal Box 8888, Station Centre-ville, Montreal, Quebec, Canada H3C 3P8. E-mail: tousignant.michel@uqam.ca

Nathalie Morin, M.Ps., Research Associate, Center for Research and Intervention on Suicide and Euthanasia, University of Quebec in Montreal. E-mail: morin.nathalie.3@uqam.ca

Livia Vitenti, Ph.D., Post-doctoral fellow, UNESCO Chair in Bioethics, University of Brasilia, Brazil. E-mail: lvitenti@yahoo.com.br 
International Journal of Child, Youth and Family Studies (2014) 5(1): 70-88

Antoine Bibaud De Serres, B.Ps., Doctoral student, Department of Psychology, University of Quebec in Montreal. E-mail: antoine.bibaud@gmail.com

Arlene Laliberté, Ph.D., Regular Professor, Department of Psychology and Psychoeducation, University of Quebec in Outaouais, Campus St-Jérôme, Quebec, Canada. E-mail:

arlene.laliberte@uqo.ca

Between 1995 and 2000, we collaborated on suicide prevention initiatives in First Nations communities where the suicide rate was rapidly rising for individuals aged 18 to 35 years. Discussions with senior members of the community and education administrators born in the community pointed to the family as a risk factor for suicide. The team then applied for a grant on the theme of suicide prevention and the family. During the planning period, it was decided not only to study families living on a reserve, but to compare them with two other groups - families living in metropolitan areas and families from small towns. The idea was first to produce as accurate a portrait as possible of how parents were actually coping with child rearing on a reserve and to see if the situation was more or less favourable outside the reserve.

A brief analysis of the epidemiology of suicide in Aboriginal communities will introduce the topic. Then, the evidence relating family factors to suicide will be presented, followed by statistics from welfare agencies on First Nations.

In Canada, the latest complete national statistics on suicide among First Nations (Government of Canada, 2006) indicated that the suicide rate for First Nations was 24 per 100,000 in 2000. This was twice the rate of the general Canadian population. The rate among First Nations men 15 to 24 years of age, was 126 per 100,000, compared to 24 per 100,000 for Canadian men of the same age. Suicide rates also vary significantly among First Nations communities, as illustrated for British Columbia by Chandler and Lalonde (1998). In Quebec, a systematic review from the coroner's office of all cases in five targeted villages from the Atikamekw and Anishnabe regions showed that for the 25 years of the period from 1986 to 2010 the number of suicides was almost one per year in three of the locations. In 2010, each of these villages had a population of 1,200 to 1,800. For the Cree, Innu, and Mohawk groups, where suicide is certainly much lower, data are scant.

Family factors have been associated with suicide both in Aboriginal and non-Aboriginal groups. There is some evidence that a history of family adversity is associated with suicidal behaviour among adolescents (Wagner, 1997). In a study using regression analysis, poor care from both parents was related to suicidal behaviour in a high school population; however, only a father's poor care was associated with suicidal behaviour in a college population (Tousignant, Bastien, \& Hamel, 1993). In a large European survey, suicide attempts among French women were associated with having an authoritarian mother, and in Spanish men with having an overprotective mother (Kovess-Masfery et al., 2011).

Brent (1995), the most quoted author in the field of adolescent suicide, concluded that parental psychopathology is associated with adolescent suicide, and presented evidence suggesting a link with parental adversity. A high score on measures of neglect and abuse was found in two-thirds of an adult suicide sample from Quebec (Zouk, Tousignant, Séguin, Lesage, \& Turecki, 2006). This 
is twice the rate of a control group of individuals who died as a result of road accidents. A New York study of youth suicide reported that parental psychopathology, especially depression in mothers and anti-social behaviour in fathers, was a predictive factor (Gould, Shaffer, Fisher, \& Garfinkel, 1998). Similarly, a large Danish study observed that suicide in a group 35 years of age and younger was associated with a history of psychiatric treatment in the mother (Stenager \& Qin, 2008). However, a study on suicide and schizophrenia failed to find any difference in parental adversity during childhood between a suicide group and a group under treatment with no history of suicide attempts. Nonetheless, the rates of parental negligence were high in both groups (Tousignant et al., 2011).

Regarding First Nations suicide, high family adversity during childhood was found in 24 cases out of 28 consecutive adult cases in four Quebec communities, (Laliberté \& Tousignant, 2009). Many cases suffered multiple types of adversity, with psychological abuse in 23 cases, physical abuse in 13, and sexual abuse in eight. Unfortunately, due to a high rate of suicidal attempts, or serious suicidal ideation among local youth, it was impossible to form a comparison group. A further analysis of this study revealed that $40 \%$ of male cases had a brother who had also died by suicide. In contrast to this finding, no single instance of two brothers having died by suicide was found in a Quebec group of 70 suicides (Zouk et al., 2006). This aggregation of suicides among brothers in First Nations might be due to genetic factors, shared family environment, or both.

Family has often been mentioned as a risk factor for Aboriginal suicide, but the evidence is incomplete. The review by Kirmayer et al. (2007) quoted many reports that showed a high incidence of traumatic family events in the Aboriginal population, especially relating to the residential schools period. However, in the absence of case-control studies only circumstantial evidence exists that these events relate to the high rate of suicides or suicide attempts in some communities. Yet, two of the seven suicide prevention guidelines produced by the consulting group target the family: (a) interventions on children and young people involving the family, and (b) training community mental health workers in individual and family counselling. A similar argument proposed in Australia suggests a link between disempowerment of families and the rise of suicidal behaviour in their children (Tsey \& Every, 2000). Summarizing theories proposed to interpret Aboriginal suicide in Australia, Hunter and Milroy (2006) concluded that all theories concur that "vulnerability" to suicide is linked to developmental factors and, thus, to those historical forces that have impacted on the environment of family life. Finally, one study reported evidence of family adversity associated with youth suicide attempts in an Inuit community of Northern Quebec and the two associated factors were a history of physical abuse (in the family or outside) and having a parent with an alcohol or drug problem (Kirmayer, Malus, \& Boothroyd, 1996). In conclusion, there is some evidence that family adversity is associated with youth suicidal behaviour among Aboriginal peoples.

The main source of data on the prevalence of abuse and negligence in families living on reserve in Canada comes from the child welfare system. A review has indicated a large overrepresentation of Aboriginal families in this category, both in Canada and in the United States (Trocmé, Knoke, \& Blackstock, 2004). In some Canadian provinces, 80\% of children in out-of-home care were Aboriginals; an estimated 76,000 Aboriginal children in Canada were in out-of-home care from 2002 to 2004, representing an increase of 70\% over the five previous years. This study also showed that disclosures to the social services were more likely to be substantiated by a professional in Aboriginal than in non-Aboriginal families. According to the authors, this higher rate in Aboriginal cases cannot be attributed to the professional biases only. In the regression analysis, the number of residential moves and unsafe housing were the two variables explaining the greatest variance in the difference in substantiated cases in the Aboriginal group. One explanation for the high 
International Journal of Child, Youth and Family Studies (2014) 5(1): 70-88

rate of Aboriginal children in the child welfare system proposes that during the residential schools period a high percentage of the generation who are now parents or grandparents suffered a long separation from family as well as multiple forms of abuse within residential schools; these individuals were deprived of learning from positive parental role models and thus could not act as positive role models for the next generation (Royal Commission on Aboriginal Peoples, 1996).

Two studies have assessed parental behaviour in Aboriginal samples. The use of the Nursing Child Assessment Teaching Skills, an observation instrument to measure parent-child interaction at an average age of 1.5 years, was used on a sample of American Indian mothers from various socioeconomic levels and these mothers had more positive interactions with their children than a group of non-Aboriginal mothers (Seideman, Jacobson, Primeaux, Burns, \& Weatherby, 1996). Their parental style was also different, more non-verbal and more observational. A comparative study with the same instrument conducted among low-income families in Edmonton, Alberta did not produce significant differences between Aboriginal and non-Aboriginal groups, but the scores in both groups were below the $10^{\text {th }}$ percentile (Letourneau, Hungler, \& Fisher, 2005).

In summary, a cautious position would consider family adversity as a likely risk factor for suicide since some evidence points in that direction, both from studies of the general population and from studies of Aboriginal peoples.

The goal of the present study was to compare how parents were coping with child rearing on a reserve and in two First Nations samples living outside reserves in order to determine if children were experiencing more family adversity in the reserve setting. Some complementary information was obtained regarding motives for leaving the reserve for individuals who had migrated, and how parents in this category evaluated life on the reserve compared to life off the reserve with respect to raising children.

\section{Sampling}

\section{Method}

\section{Metropolitan group $(N=40)$}

Because no list of Aboriginal families outside reserves exists, the Metropolitan sample was a sample of convenience. Of the 40 informants, 27 were recruited in the Greater Montreal Area and 13 in the Greater Quebec City Area. The task was difficult in Montreal, where approximately 7,000 residents of Aboriginal origin are scattered over the Metropolitan area. Aboriginal associations were contacted, mainly through the Centre d'amitié autochtone de Montréal (Native Friendship Centre of Montreal) and the University of Quebec Association of Aboriginal Students. These associations did not work directly with families. We also used the snowball technique with the first respondents. In Quebec City, a team member of Innu origin helped identify numerous informants.

\section{Small town group $(N=15)$}

The definition of small town has been borrowed from Statistics Canada and refers to a city with a population of more than 2,000 but not integrated into a metropolitan area, which is defined as a city of more than 100,000 integrating many municipalities. The towns covered were La Tuque, Joliette (Atikamekw) as well as Val d'Or and its vicinity (Anishnabe). In these locations the 
International Journal of Child, Youth and Family Studies (2014) 5(1): 70-88

Aboriginal families knew each other and the snowball technique as well as recruitment through local organizations were used.

\section{Reserve group $(N=12)$}

Introducing a research program on a reserve can require many months. For this reason, the research was limited to a single village in the Anishnabe territory. One difficulty to recruiting on the reserve was the fear that the interview program was related with the child welfare services. In the years leading up to and including the time of the interviews, there had been many suicides and reported suicide attempts on this reserve.

\section{Selection criteria}

Each informant was responsible for at least one child under the age of 18 years and was a permanent resident of the geographical milieu to which he or she was assigned. All informants were registered as Indians according to the Indian Act of Canada.

\section{Socio-demographic characteristics}

The majority of the metropolitan group was of Innu origin $(N=22)$, mostly from Quebec City. Other represented nations were Anishnabe (6), Atikamekw (4), Micmac (3), Mohawk (2), and Inuit (1). The small town group was evenly distributed between Atikamekw and Anishabe. Apart from a single Cree informant, all informants on the reserve were Anishnabe.

Two-thirds of the metropolitan group had completed high school (11th grade in Quebec) or a higher degree. In the reserve and small town groups, half had completed high school or earned a higher degree while half had not completed high school. However, according to census data on the reserve selected for this study, only $20 \%$ had completed high school.

The reserve group had the highest number of biological children, 3.6, compared to 2.23 for the metropolitan group and 3.0 for the the small town group.

\section{Instrument}

The interview was introduced as an informal exchange about the ways Aboriginal parents were coping with their children. The first section focused on family of origin and quality of the relationships with the parents. Informants were asked to describe life at home during their childhood years. For those who had left a reserve, some questions focused on the reasons for and circumstances of leaving the community. The second section focused on the actual family.

The central part of the questionnaire focused on how the parent was coping with rearing children, both in the present and in the past. An effort was made to introduce the questions in a neutral way and to gather concrete examples of daily life in order to obtain a reliable portrait of family life and avoid general statements. The interview covered the main domains of the CECA's negligence/indifference scale and questions pertained to activities such as helping the child with school, caring for health problems, providing supervision, providing a minimal structure for daily life 
(meals, bedtime), and using services to solve problems. Particular attention was given to the parent's capacity to get involved in the child's development as opposed to passively coping (or not coping) with daily problems. The interviews were analyzed with the Nvivo software program which classifies corresponding sections of interview transcriptions into defined themes, for example "grandparents" or "cultural identity".

A central task was to score negligence/indifference in the parent-child relationship. To this end, we borrowed the criteria of a validated instrument, the Childhood Experience of Care and Abuse interview or CECA (Bifulco, Brown, \& Harris, 1994) which the first author had used in other studies. Although we did not ask all the questions contained in the CECA because we were not using all the scales, we did use many of the original instrument's questions relating to child care. The material obtained provided concrete illustrations of daily parental behaviour and was adequately explicit to score the negligence/indifference scale.

The coding was based on the corpus of examples from the original authors which includes many instances for each level of the negligence/indifference scale. Scores range from 1 to 4, with 1 being the most severe. A score of 1 (Severe) corresponds to high or severe negligence/indifference and a score of 2 (Moderate) corresponds to moderately severe negligence/indifference. Both these highest scores of severity are usually reduced to one category for the analyses. Numerous studies have demonstrated that these scores are associated with vulnerability to depression at the adult stage (Brown, Craig, Harris, Handley, \& Harvey, 2007).

Characteristics of a score of 1 are, for instance, a high level of violence in the family, placement of children in foster care, or leaving children alone overnight. In one example, the mother who had recently given birth had been drinking during her pregnancy; her three other children had been placed in a foster home. There was both physical violence and a lack of food in the home. A score of 2, or a moderate negligence level, is also considered detrimental to the child's development. One example includes a mother and father who lived together with their two children, 5 years and 20 months. The mother had little support from her partner who drank heavily and did not provide support for childcare tasks such as accompanying a sick child to the hospital. There was no regular schedule for home activities; the mother did not like cooking and regularly ate at her own mother's house. The household hosted parties that lasted three days during which time the mother didn't sleep. However, in this household there was no violence. Scores of 3 indicate some negligence and scores of 4 indicate none at all.

An example of a score of 3 (Some) is a woman who had children and a boyfriend not living with her. She raised the children in poverty, engaged in therapy to gain greater control of her life, and finally obtained a job as an assistant social worker. Despite her many problems, she found resources to help her with family life. A score of 4 (None) usually reflects parents who take active responsibility when problems with children arise and behave proactively. For example, one mother rated 3 (Some) when, as an adolescent, she had her first child and received no support from the father. Later, she had two more children and received good support from her new partner. She used her resources in order to face problems, and completed both an undergraduate degree and a master's degree while raising two pre-schoolers. At this time she rated a score of 4 (None). We saw other examples where a parent scored positive for negligence in the first stage of parenthood, but the situation had sufficiently improved at the time of the interview to attain a score of 3 or 4 . In these cases, we decided to code the negative score corresponding to 1 or 2 to reflect the fact that at least 
International Journal of Child, Youth and Family Studies (2014) 5(1): 70-88

one of the children had been at risk, having lived for a significant period in a state of parental negligence.

Complementary information on family life on the reserve in general was obtained through a First Nations project assistant who lived on the reserve, interviews with professionals and agents working in the community (such as the police and the schools directors), focus groups with exstudents of residential schools, and the local advisor committee.

\section{Procedure}

Most interviews were completed at the home of the informant by a team of two psychology students and two anthropologists. Two First Nations students did the recruiting. The informant received a small financial compensation. The coding of the interview results was done by the first three authors using consensus. On average, interviews lasted 1.5 hours.

\section{Ethical considerations}

The project was approved by the ethical committee of the University of Quebec in Montreal. The Canadian Tri-Council guidelines for research with Aboriginal peoples were applied (Canadian Institutes of Health Research, Natural Sciences and Engineering Research Council of Canada, and Social Sciences and Humanities Research Council of Canada, 2010).

A formal approval was provided by the Chief and Council of the reserve. There was also an advisory committee from the reserve composed of seniors and members involved in social services. This committee met with the team twice a year to guide the research orientation and assist in the transfer of knowledge.

\section{Results}

The central focus of this paper (Table 1) compared parental negligence or indifference in the three residential groups. There was a small but significant difference favouring the metropolitan group compared to the reserve group $\left(\mathrm{X}^{2}=4.48 ; d f=1 ; p<.05\right)$.

The negligence scores for the informants' family of origin are approximate since, in some cases, there was insufficient material to support assignment of a code. A few informants simply mentioned, without elaboration, that "people were drinking all the time" or that "my childhood was miserable". We believe that such statements refer to serious negligence, but the supporting information is too vague to confidently assign a code. The statistics provided are exploratory and approximate regarding the level of adversity in the family of origin - no statistical tests were conducted on these data. The family situation may be improving in the metropolitan group compared to their family of origin, but the evidence is not as clear in the other two groups and there is no statistical evidence because the section of the interview on the family of origin was too superficial. 
International Journal of Child, Youth and Family Studies (2014) 5(1): 70-88

Table 1. Presence of negligence towards children in the informant's family of origin and in his present family

\begin{tabular}{|c|c|c|c|c|}
\hline \multirow[t]{2}{*}{ Family } & & Metronolitan & Small town & Reserve \\
\hline & & $(N=39)^{1}$ & $(N=15)$ & $(N=12)$ \\
\hline \multirow[t]{2}{*}{ Present } & Positive & $19(49 \%)^{2}$ & $10(67 \%)^{2}$ & 10 (83\%) \\
\hline & Some/None & 20 (51\%) & $5(33 \%)$ & $2(17 \%)$ \\
\hline \multirow[t]{2}{*}{ Origin } & Positive & 27 (71\%) & 10 (67 \%) & 12 (100 \%) \\
\hline & Some/None & $11(29 \%)$ & 5 (33\%) & $0(0 \%)$ \\
\hline
\end{tabular}

${ }^{1}$ One missing value

${ }^{2}$ Five families in the metropolitan group and two in the small town groups scored positive on negligence in the past years but not at the time of the interview.

Table 2. Problems spontaneously reported in the history of the actual family

$\begin{array}{ccc}\text { Metropolitan } & \text { Small town } & \text { Reserve } \\ (N=39)^{1} & (N=15) & (N=12)\end{array}$

Violence

Sexual violence

$0 \quad 1$

2

Extreme negligence

0

0

2

Marital violence

6

2

2

Other violence

0

0

3

Suicide

0

2

2

Any type of violence

6

4

8 
International Journal of Child, Youth and Family Studies (2014) 5(1): 70-88

Addiction problems

\begin{tabular}{lccc} 
Alcohol & 18 & 9 & 11 \\
Drugs & 10 & 3 & 3 \\
Gambling & 0 & 0 & 0 \\
\hline & & & \\
\hline
\end{tabular}

From the interviews, we recorded the number of times various types of violence were mentioned (Table 2). Instances of violence were higher in the reserve group (8/13 or 61\%) than in the metropolitan group (6/40 or 15\%); the small town group was in the intermediate position (4/15 or $27 \%)$. Problems with alcohol were almost universal on the reserve (11/13 or $85 \%)$, much lower in the metropolitan group (18/40 or $45 \%)$, with the small town group (9/15 or $60 \%)$ again falling in between.

The context of migration can provide important information about families from the nonreserve groups. High geographical mobility was present in both groups. In the metropolitan group, only seven informants were born in a large city; three of these had lived on a reserve for more than a year during childhood. More than 80 \% (28) had spent at least half their childhood on a reserve. Finally, of the 31 informants born on a reserve in that group, more than half (17) had moved to a small town before settling in a metropolitan area. A majority of informants (11) from the small town group were also born on a reserve - three had lived in a city at some point, and three had moved back to the reserve at some point. Of the 11 informants with data from the reserve, five had always lived on the reserve, four had lived in a small town, and two in a metropolitan area. The main conclusion from these statistics is that there is high residential mobility in the first two groups, and that the reserve had a strong influence on informants’ lives.

The reasons for leaving the reserve were varied. As shown in Table 3, the most frequently stated reason in both groups was to complete education. All these informants had settled permanently in their new environment and had no intention of returning to the reserve in the near future. The second most frequent reason, also in both groups, was to escape adverse conditions of family life on the reserve: for example, escaping from an aggressive partner, avoiding falling back into heavy drinking, or protecting one's children. The third and fourth reasons mentioned by $40 \%$ of the metropolitan group related to accompanying a parent when the informant was still a child, accompanying a spouse who had decided either to study or work, or to join family members living outside the reserve. To summarize, migration was motivated more by "pull” factors than by "push" factors in the terms used by the immigration literature. 
International Journal of Child, Youth and Family Studies (2014) 5(1): 70-88

Table 3. Reasons for leaving the reserve

Metropolitan group

$(N=34)^{1}$
Small town group

$$
(N=8)
$$

Education

Escape a situation

13

Accompany a spouse

7

6

Accompany a parent

Work

5

Specialized health care

2

Status problem

1

0

33

22

$0 \quad 0$

$0 \quad 0$

11

$0 \quad 0$

$1 \quad 1$

\footnotetext{
${ }^{1}$ Seven missing values in each of the two groups
} 
International Journal of Child, Youth and Family Studies (2014) 5(1): 70-88

Table 4. Perceptions of the challenges and strengths of the reserve and the nonreserve environments with regard to raising children ${ }^{1}$

\begin{tabular}{lccc}
\hline & Metropolitan & Small town & Reserve \\
Limitations of the reserve & 19 & 7 & 5 \\
Social problems & 11 & 3 & 5 \\
Lack of supervison & 7 & 1 & 2 \\
Danger of sexual abuse & 7 & 2 & 2 \\
Absence of privacy & 0 & 3 & 3 \\
Insecurity & 4 & 1 & 1 \\
Lack of work & 3 & 1 & 1 \\
Women' s status & 3 & 1 & 1 \\
Burden of confidences & 2 & 0 & 2 \\
Leadership & & & 3 \\
$\quad$ Strengths of the reserve & 8 & 0 & 2 \\
Family support & 5 & 1 & 3 \\
Traditional life & 4 & 0 & 3 \\
Freedom of children & 0 & 0 & \\
Social development & & & \\
\hline
\end{tabular}

Another important interview theme was comparing perceptions of the three groups in terms of what environment (reserve or city) was perceived as better for raising children. Table 4 lists the problems and advantages participants reported for each setting. This information can help to interpret possible differences in parental behaviours among the three groups. In all three groups about half of the informants mentioned the numerous social problems (particularly alcohol and violence) as the main liability of living on a reserve and raising children there. The second biggest liability of the reserve (mentioned by one-third of all informants) was the general lack of children's supervision by their parents, meaning that non-supervised children could have a negative influence on their own children in terms of socialization to drugs and alcohol.

Though mentioned by only one-fifth of informants, family support was reported as the main strength of living on the reserve. The other two most positive characteristics were the strength of traditional life (though some informants emphasized that they were 
International Journal of Child, Youth and Family Studies (2014) 5(1): 70-88

referring to life in the forest and not to life on the reserve), and the freedom of children to play on the streets without parental supervision, meaning that traffic was not a danger and that passers-by would keep an eye on children.

\section{Discussion}

\section{Family adversity}

We will first look at the evidence that family adversity is a risk factor for youth Aboriginal suicide. The existence of suicide clusters among brothers, and the high level of family adversity during childhood could support either a genetic or an environmental explanation (Laliberté \& Tousignant, 2009). Another clear result from that study was that the rate of severe parental negligence was found to be very high in a series of 30 First Nations suicides. There was, however, no control group in that study. The problem is that suicide is a rare event and when suicide is frequent enough to launch a study in a community, suicidal behaviour and ideation are also found to very high, making it almost impossible to form a non-suicidal control group (not to mention a non-suicidal clinical group). Nevertheless, with the knowledge currently available many authors and Aboriginal community leaders, both in Canada and Australia, agree that we should target the family environment in suicide prevention strategies.

To summarize the results of this study, despite the low number of informants in the reserve group, cases of negligence/indifference were statistically lower in the metropolitan group than in the reserve group. More than a third (36\%) of the metropolitan group was classified positive on negligence in the period immediately preceding the interview, compared to a rate of negligence of $82 \%$ in the reserve group. However, the presence of negligence/indifference was high in all three groups compared to other surveys in youth populations where it is generally below 20\% (Tousignant et al., 1993). Keeping in mind that the situation is somewhat better in the metropolitan group, we can nevertheless conclude that a high number of children in all three groups will be vulnerable to mental health problems and suicidal behaviour as they grow older.

The following story illustrates the improvement of life after migrating to the city. At the time of the interview, Eulalie Wanaban (not her real name) had a 10-month-old daughter and a non-Aboriginal partner who held a good job. At 18 she had left the reserve to live with a sister, and at 20 moved to another town. At 22 she was drinking heavily and was pregnant; the father was absent. She was on drugs and alcohol during the first years of her son's life but she wanted a better life for him. At 25 she underwent a religious conversion and stopped consuming drugs and alcohol. At 32 she met her future husband. At the time of the interview, both held jobs and were involved with the child's activity. She had a 15-year-old nephew living at her home as well as two nieces during summertime.

The statistics of the local Centre Jeunesse (Child Welfare Services) corroborates the high rate of negligence on the reserve. About $40 \%$ of the children in that village had experienced an out-of-home placement at some time during their childhood. This is much 
International Journal of Child, Youth and Family Studies (2014) 5(1): 70-88

higher than the Canadian average for Aboriginals. Furthermore, a child on that reserve had about a $70 \%$ chance of being reported to the Child Welfare Services before reaching the age of 18 .

The results obtained on the reserve should be put into perspective. Although the presence of negligence/indifference indicates a high-risk situation for a child, negative experiences were not necessarily a daily experience. As stated in a previous study on family and First Nations suicide, when the parents were not drinking, the family situation was often perceived as positive and the informants provided an idealized image of their parents (Laliberté \& Tousignant, 2009). This portrait contrasts with case studies from the general Quebec population where the abuse or negligence was reported as more systemic and associated with chronic personality problems in the parents (Zouk et al., 2006).

These rather gloomy statistics regarding family life on the reserve obscure some positive counterbalancing elements. As shown in both this study (see Table 4) and in a national survey (The First Nations Information Governance Centre, 2012), the family is still the strongest source of support to individuals. Although a high number of families are in distress, they are not as isolated as those in the general population scoring high on negligence. The fact that placements within the family are increasing (rather than outside the family or community) indicates that family solidarity is strong on reserves. Despite historical trauma and major challenges for families, there are many resilient families to be found.

The following story of a couple from the reserve illustrates the negative/positive cycle of family life and the presence of resilience in the middle of adversity. Before their union, both partners had tremendous difficulties with children from separate unions. All their children had been placed in care. At the time of the interview they had a threemonth-old child, and they had stopped drinking in order to provide him with positive and effective care. They had both started to do volunteer work with seniors, and the mother planned to return to school. The father worked full time outside the community, but complied when asked to take care of the child. Family members came to the home to help the mother.

The interviews suggest two explanations for the overall lower levels of negligence/indifference in the metropolitan group. First, there might be a selection factor at work as people exposed to lower levels of negligence/indifference leave the reserve to seek a better quality of life through employment or education. The other explanation may lie in the separation from a violent partner. In this regard, there were several crosscultural couples in both the metropolitan group and the small town group, but not in the reserve group, likely due to the small number of persons from the same First Nation background available for a second union.

\section{Ecology of the family}

The more positive portrait of the metropolitan group may be partially explained by environmental factors. The ecology of the family can be an important buffer to other 
problems. In families where negligence was present, children had the advantage of external sources of protection compared to children on the reserve. In these families, school appeared to mitigate the negative effects of the home environment, much more than for the reserve group, by offering the child more supervision and structure. The city school seems to better integrate the child academically and to increase the probability of high school completion. This is a general impression that needs to be validated by more systematic analysis. This tentative conclusion is in no way intended to be critical of the quality of reserve schools. On the contrary, the staff of the reserve schools visited during this project were highly competent and their achievements remarkable. For adolescents on the reserve the high school environment is also challenging. A young person with academic interests may be rejected by his or her peers. As well, they are exposed to numerous youth suicide attempts, and even to the occasional suicide. A possible initiative to help children in reserve schools would be the introduction of mental health promotion programs. One team within our program developed a culturally-adapted intervention based on art therapy and philosophy for children. This program, named Nokitan II, was run on a trial basis in Wemotaci. Its objective was to help children express their feelings and learn tools to negotiate solutions rather than act out their feelings (Rousselot, 2009).

Another observation of family ecology in the metropolitan area was that children were less directly exposed to community violence or to disturbances from drunken visitors in the home. It seemed easier to maintain a calmer home environment in the big city than on the reserve, even in cases of negligence. A sub-group of families with negligence in the metropolitan area was formed by single mothers, who were socially isolated and feeling a bit lost and overwhelmed by the complex adaptation to urban life. In this sub-group, there was generally no violence, alcohol abuse, or intrusion by undesirable visitors.

\section{Collateral effect of migration}

One likely effect of the migration from the reserve is the drain of members with a higher interest in education who might have positively contributed to the community. Though the migration trend is not (at the moment) demographically important, it should be a consideration when assessing the social capital of a reserve. On the other hand, in the reserve group, many informants had lived outside the reserve. When they migrate back to their community, they could possibly bring the advantage of their experience of dealing with the non-Aboriginal world. But, on the whole, the net migratory balance seems negative for the reserve.

\section{Limitations of the research}

The convenience nature of the three samples is likely to introduce biases. In this study, it was possible to document that the reserve sample included informants with a higher than average education for their community, where rarely more than five students graduate from high school annually. Due to fear that information would get back to welfare services, there was also a mistrust on the reserve regarding interviews on parentchild relationships. 
International Journal of Child, Youth and Family Studies (2014) 5(1): 70-88

In the absence of a list of First Nations members living in small towns and metropolitan groups, it is difficult to assess the degree of representativeness of our samples. Families with children were not easy to identify and reach, and the snowball technique is the only one we could use in these circumstances. Therefore, it is difficult to assess the generalizability of the results. Besides, the Montreal area covers many First Nations groups, unlike the reserve and small town groups. The composition of our samples reflects the heterogeneity of the population and the difficulty of doing this type of research.

\section{Lessons for prevention}

The level of family distress on the reserve selected for this study is still quite high, and the present generation of children is likely to carry increased vulnerability for suicide. Although this problem is widely acknowledged, the solutions are complex and need to focus simultaneously on many targets.

The goal of this paper was to describe family life in three geographical settings. From interview information we can suggest the nature of the needs of some families, but it is difficult to extrapolate which interventions are most likely to diminish negligence. Meanwhile, some reserves are experiencing an acute crisis situation and we must propose concrete actions even given the partial knowledge available. Consequently, guided by the interviews and drawing on six years of field experience of life on reserves, we will offer some tentative guidelines for intervention. We are aware, however, of the lack of evidence - both from the results and from our knowledge of the literature - that these recommendations will decrease suicidal behaviour.

One small step towards diminishing negligence would be to work to reduce the number of births to adolescents, but this issue is sensitive and should be introduced with great care. These early births appear to lead to more placements compared to births later in life. Several interviews clearly showed that mothers did very well with the later-born children, but they ran into serious difficulties at adolescence with their first-born child. For this type of prevention, birth control or abortion are not solutions easily acceptable to the culture, still strongly influenced by Catholicism. Strategies should be proactive rather than repressive and provide adolescents with goals and a sense of meaning for their future life (Catalano Hawkins, Berglund, Pollard, \& Arthur, 2002).

Services and programs on reserves in Quebec are usually high, and one author used the concept of "overmedicalization" to describe his observations (Roy, 2009). In the reserve under analysis, the social welfare personnel was as large as in the nearby town with a population of about 40,000. Prevention programs were plentiful and some families simultaneously dealt with numerous service providers. The challenge was to better coordinate social service actions, to define the goals to be achieved with the family, and to encourage parent participation. 
International Journal of Child, Youth and Family Studies (2014) 5(1): 70-88

Alcohol and drugs are a serious handicap to positive parental behaviour, and negligence is associated with long periods of parental intoxication. Spontaneous reports of alcohol problems within the family were very high on the reserve. There were also many violent incidents during these intoxications. Initiatives should be taken to protect the children during these periods, with refuge homes for victims of violence and abandonment. Protection of children is perhaps one of the biggest challenges facing communities in crisis. Social services and the justice system should use culturallyadapted interventions with the support and collaboration of the most respected members of the extended family (Tousignant, Morin, \& Vitenti, 2013). Excellent guidelines have been proposed for nearly two decades, but with little effect on controlling violence in communities (Native Women's Assciation of Canada, 1994).

Another intervention is to provide parents opportunities to become more involved with their children. Prevention programs will probably attract the more motivated parents, but not necessarily parents most in need. A review of the literature has shown that successful programs are those that centre on issues proposed by the parents and focus on concrete behaviours (Tousignant \& Sioui, 2009). One original initiative observed on the reserve was a school director who asked fathers to come to the school to help her control their children's behaviour.

Solutions should not only target parental behaviour, but should contribute to increasing the quality of life in homes. Providing employment would improve the selfesteem of parents, structure parents' time, and structure their living habits. Crowding and the quality of housing is also a chronic problem that needs urgent action as seen in Trocme et al. (2004). Families often host friends and members of the extended family who have been rejected from other homes, and whose presence can put children at risk.

A positive transition into adulthood and parenthood is a key to strengthening new families. Young parents need education to find job opportunities in order to secure a place in our globalized world. On the reserve, the outside world is not always perceived realistically, and some informants idealized their children's future, fantasizing unlikely scenarios like becoming a professional hockey player. The absence of motivation for school achievement and the high drop-out rate might be counterbalanced by a continuous education program adapted to youth needs and including parental skills. Theoretically, this failed transition to adulthood is fed by a lack of self and cultural continuity, a concept central in the etiology of First Nations suicide (Chandler \& Lalonde, 1998). 
International Journal of Child, Youth and Family Studies (2014) 5(1): 70-88

\section{References}

Bifulco, A., Brown, G. W., \& Harris, T. O. (1994). Childhood experience of care and abuse (CECA): A retrospective interview measure. Journal of Child Psychology and Psychiatry, 35(8), 1419-1435. http://dx.doi.org/10.1111/j.1469-7610.1994.tb01284.x

Brent, D. A. (1995). Risk factors for adolescent suicide and suicidal behaviour: Mental and substance abuse disorders, family environmental factors, and life stress. Suicide and Life-Threatening Behavior, 25(Suppl.), 52-63.

Brown, G. W., Craig, T. K., Harris, T. O., Handley, R. V., \& Harvey, A. L. (2007). Development of a retrospective interview measure of parental maltreatment using the Childhood Experience of Care and Abuse (CECA) instrument: A life-course study of adult chronic depression -1. Journal of Affective Disorders, 103(1-3), 205-215. http://dx.doi.org/10.1016/j.jad.2007.05.022

Canadian Institutes of Health Research, Natural Sciences and Engineering Research Council of Canada, \& Social Sciences and Humanities Research Council of Canada. (2010). Tri-council policy statement: Ethical conduct for research involving humans. Ottawa: Authors.

Catalano, R. F., Hawkins, J. D., Berglund, M. L., Pollard, J. A., \& Arthur, M. W. (2002). Prevention science and positive youth development: Competitive or cooperative frameworks? Journal of Adolescence Health, 31(6), 230-239. http://dx.doi.org/10.1016/s1054-139x(02)00496-2

Chandler, M. J., \& Lalonde, C. (1998). Cultural continuity as a hedge against suicide in Canada's First Nations. Transcultural Psychiatry, 35(2), 191-219. http://dx.doi.org/10.1177/136346159803500202

Gould, M. S., Shaffer, D., Fisher, P., \& Garfinkel, R. (1998). Separation/divorce and child and adolescent completed suicide. Journal of the American Academy of Child \& Adolescent Psychiatry, 37(2), 155-162. http://dx.doi.org/10.1097/00004583-199802000-00007

Government of Canada. (2006). Aboriginal mental health and well-being. In The human face of mental health and mental illness in Canada (Chapter 12). Ottawa: Minister of Public Works and Government Services Canada. www.phacaspc.gc.ca/publicat/human-humain06/index-eng.php.

Hunter, E., \& Milroy, H. (2006). Aboriginal and Torres Strait Islander suicide in context. Archives of Suicide Research, 10(2), 141-157.http://dx.doi.org/10.1080/13811110600556889

Kirmayer, L. J., Brass, G. M., Holton, T., Paul, K., Simpson, C., \& Tait, C. (2007). Suicide among Aboriginal people in Canada. Paper prepared for the Aboriginal Healing Foundation, Ottawa. 
International Journal of Child, Youth and Family Studies (2014) 5(1): 70-88

Kirmayer, L. J., Malus, M., \& Boothroyd, L. J. (1996). Suicide attempts among Inuit youth: A community survey of prevalence and risk factors. Acta Psychiatrica Scandinavica, 94(1), 8-17. http://dx.doi.org/10.1111/j.1600-0447.1996.tb09818.x

Kovess-Masfety, V., Boyd, A., Haro, J. M., Bruffaerts, R., Villagut, G., Lépine, J. P., et al. (2011). High and low suicidality in Europe: A fine-grained comparison of France and Spain within the ESEMeD surveys. Journal of Affective Disorders, 133(1/2), 247-256. http://dx.doi.org/10.1016/j.jad.2011.04.014

Laliberté, A., \& Tousignant, M. (2009). Alcohol and other contextual factors of suicide in four Aboriginal communities of Quebec. Crisis, 30(4), 215-221. http://dx.doi.org/10.1027/0227-5910.30.4.215

Letourneau, N. L., Hungler, K. M., \& Fisher, K. (2005). Low-income Canadian Aboriginal and non-Aboriginal parent-child interactions. Child: Care, Health \& Development, 31(5), 545-554. http://dx.doi.org/10.1111/j.1365-2214.2005.00549.x

Native Women's Association of Canada. (1994). Aboriginal women: Police charging policies and domestic violence. Ottawa, ON: Author.

Rousselot, D. (2009). Évaluation de la phase dimplantation du projet Nokitan II [Evaluation of the implementation stage of project Nokitan II]. Master's thesis. Faculty of Education, University of Montreal.

Roy, B. (2009). Peut-on attribuer le mauvais état de santé des Autochtones à leur exclusion du système de soins de santé? [Can we attribute Aboriginals' bad health state to their exclusion from the system of health services?]. In E. Gagnon, Y. Pelchat, \& R. Edouard (Eds.), Politiques d'intégration, rapports d'exclusion [Policies of integration, dynamic of exclusion] (pp. 169-186). Québec: Presses de l'Université Laval.

Royal Commission on Aboriginal Peoples. (1996). Choosing life: Special report on suicide among aboriginal people. Ottawa: Canada Communication Group.

Seideman, R., Jacobson, S., Primeaux, M., Burns, P., \& Weatherby, F. (1996). Assessing American Indian families. American Journal of Maternal Child Nursing, 21(6), 274-278. http://dx.doi.org/10.1097/00005721-199611000-00012

Stenager, K., \& Qin, P. (2008). Individual and parental psychiatric history and risk for suicide among adolescents and young adults in Denmark: A population based study. Social Psychiatry and Psychiatric Epidemiology, 43(11), 920-926. http://dx.doi.org/10.1007/s00127-008-0385-2

The First Nations Information Governance Centre. (2012). Community wellness (Chapter 16). In First Nations regional health survey (RHS) phase 2 (2008/10), National 
International Journal of Child, Youth and Family Studies (2014) 5(1): 70-88

report on adults, youth and children living in First Nations communities (pp. 204210). Ottawa: Author.

Tousignant, M., \& Sioui, N. (2009). Resilience and aboriginal communities in crisis: Theory and interventions. Journal of Aboriginal Health, 5(1), 43-61.

Tousignant, M., Bastien M. F., \& Hamel, S. (1993). Suicidal attempts and ideations among adolescents and young adults: The role of father and mother care and parents separation. Social Psychiatry and Psychiatric Epidemiology, 28(5), 256261.

Tousignant, M., Morin, N., \& Vitenti, L. (2013). Aboriginal youth suicide in Quebec: The contribution of public policies to prevention. International Journal of Law and Psychiatry, 35(5/6), 399-405.

Tousignant, M., Pouliot, L., Routhier, D., Vrakas, G., McGirr, A. \& Turecki, G. (2011). Suicide and schizophrenia: Role of life events and childhood factors. Suicide and Life-Threatening Behavior, 41(1), 66-78. http://dx.doi.org/10.1111/j.1943-278x.2010.00002.x

Trocme, N., Knoke, D., \& Blackstock, C. (2004). Pathways to the overrepresentation of Aboriginal children in Canada's child welfare system. Social Service Review, 78(4), 577-600. http://dx.doi.org/10.1086/424545

Tsey,K., \& Every, A. (2000). Evaluating Aboriginal empowerment programs: The case of family well-being. Australian and New Zealand Journal of Public Health, 24(5), 509-514. http://dx.doi.org/10.1111/j.1467-842x.2000.tb00501.x

Wagner, B. M. (1997). Family risk factors for child and adolescent suicidal behavior. Psychological Bulletin, 121(2), 246-298. http://dx.doi.org/10.1037/0033-2909.121.2.246

Zouk, H., Tousignant, M., Séguin, M., Lesage, A., \& Turecki, G. (2006). Characterization of impulsivity in suicide completers: Clinical, behavioral and psychosocial dimensions. Journal of Affective Disorders, 92(2/3), 195-204. http://dx.doi.org/10.1016/j.jad.2006.01.016 